\title{
Serviços Educacionais: ferramenta para compreensão do papel de Foz do Iguaçu/ PR na rede urbana
}

Cláudia Heloiza Conte*

Resumo: 0 presente trabalho tem como objetivo analisar os serviços de educação enquanto atividade que insere a cidade de Foz do Iguaçu em uma rede de cidades. Isto permite entender que a análise de uma cidade em dada rede urbana deve ser realizada a partir de mecanismos e atividades como percurso ao entendimento das complexas interações espaciais. A partir de 1970, com a construção da Usina Hidrelétrica de Itaipu, Foz do Iguaçu passou por inúmeras transformações que alteraram a sua dinâmica. Entre estas transformações podemos apontar o incremento e o aperfeiçoamento da oferta de bens e serviços para sua população e para as cidades da rede. Partindo desta base, realiza-se uma breve discussão das principais características de rede urbana e suas especificidades. Apresenta-se um panorama das instituições de ensino de Foz do Iguaçu e analisa-se a utilização destes serviços pelas cidades da rede urbana regional e pelas cidades vizinhas de Ciudad Del Este no Paraguai e Puerto Iguazu na Argentina. A partir destas análises, procura-se verificar a inserção da cidade na rede urbana por meio do setor educacional. Maringá
Universidade Estadual de

\section{Educational Services: tool for understanding the role of Foz do Iguaçu / PR network in urban}

Palavras-chave: Rede urbana; Serviços; Educação; Foz do Iguaçu.

Key-Words: Urban network; Services; Education; Foz do Iguaçu.

\begin{abstract}
The present work aims to analyze education services as an activity that enters Foz do Iguaçu city in a network of cities. This allows us to understand that the analysis of a given city in the urban network must be made from mechanisms and activities such as rute to understanding the complex spatial interactions. From 1970 with construction of Itaipu Hydroelectric Power Plant Foz do Iguaçu went through many changes that have altered its dynamics. Among these transformations we can point to the increase and improvement of supply of goods and services to its population and the cities of network. On this basis we make a brief discussion of the main features of the urban network and its specifities. Its presents an overview of the education institutions of Foz do Iguaçu and analyzes the use of this services by regional urban network of cities and the neighboring cities of Ciudad Del Este in Paraguai and Puerto Iguazu in Argentina. From these abalyzes we attempt to verify the insertion of the city into the urban network through the education sector.
\end{abstract}




\section{Introdução}

A partir da década de 1970 a rede urbana brasileira passou por fortes transformações, que de acordo com Corrêa (2006), são determinadas por alterações ocorridas na organização socioespacial. Essas alterações podem ser caracterizadas pela desconcentração, ampliação e diversificação das atividades industriais, com o aparecimento de centros industriais diversificados e especializados, além da modernização, industrialização e capitalização do campo.

Diante disso, é fundamental o reconhecimento dos novos papéis e valores desempenhados pelas cidades e regiões. Torna-se importante também identificar as novas funções urbanas e as novas interações espaciais que delas derivam, como as relações cidade-região e as relações interurbanas. Tais mudanças determinam as novas formas de inserção das cidades na rede urbana, alterando desta forma seus aspectos estruturais.

Marco importante deste processo, a construção da Usina Hidrelétrica de Itaipu, se inseriu nesta dinâmica de transformações da economia brasileira e permitiu o estabelecimento de novas relações econômicas no Brasil e de Foz do Iguaçu com sua rede regional de cidades e com seus vizinhos sul-americanos. Com a construção da Usina Hidrelétrica de Itaipu, a cidade apresentou crescimento e considerável desenvolvimento econômico, caracterizado principalmente por aquilo que Bessa (2005) considerou de produção não material, ou seja, comércio e prestação de serviços. Esta materialidade permitiu que ocorresse a expansão das funções urbanas, o que de certa forma criou maior complexidade funcional para a cidade.

Tendo em vista o crescimento das atividades relacionadas aos setores de serviços e comércio em Foz do Iguaçu, optamos por verificar e analisar os serviços de educação na cidade, bem como a influência destes serviços no que diz respeito à dinâmica da rede de cidades. Para tanto, 0 trabalho se propõe a apresentar conceitos e características de rede urbana, analisar os serviços de educação com ênfase no ensino superior, além de verificar a abrangência destes serviços através dos fluxos populacionais e das cidades que utilizam tais serviços.

Em relação à coleta de dados, cabe apontar que foram realizadas pesquisas quantitativas e qualitativas. As quantitativas na perspectiva de compreender o número de alunos que as instituições de ensino superior de Foz do Iguaçu atendem, enquanto a pesquisa qualitativa se deu por meio de entrevistas com diretores e/ou responsáveis de cada instituição, a fim de buscar informações específicas sobre a demanda das cidades da rede urbana regional, bem como do Paraguai e da Argentina. Todas as instituições de ensino superior responderam aos questionários, fato que possibilitou uma análise completa no que diz respeito ao papel exercido por Foz do Iguaçu na rede de cidades através do ensino superior.

\section{Rede Urbana}

Ao buscarmos por estudos acerca desta temática, encontramos uma vasta produção teórica que procurou e procura compreender a rede urbana com base em distintos elementos e/ou categorias analíticas, sendo os estudos sobre a hierarquia urbana os mais numerosos e tradicionais. Christaller, estudioso alemão, em 1933 escreveu a teoria das Localidades Centrais, explicando a

Geografia Ensino \& Pesquisa, v. 17, n.1 p. 15-26, jan./abr. 2013

Serviços Educacionais: ferramenta para compreensão do papel de Foz do Iguaçu/ PR na rede urbana distribuição de bens e serviços pelas cidades. 0 autor verificou que existe distinção entre a distribuição de bens e serviços entre as cidades, vinculada diretamente ao tamanho dos núcleos.

As proposições de Christaller referem-se à análise dos núcleos urbanos diversos, entendidos como localidades centrais, nos quais se realizam funções centrais de distribuição de bens e serviços a uma população residente em sua área de influência. Para o autor, as localidades centrais apresentam diferentes níveis de centralidade, enquanto graus variados de importância, a partir das funções centrais desempenhadas. 
De acordo com a teoria das Localidades Centrais, a rede urbana pode ser compreendida segundo a função das localidades, pois "[...] existem princípios gerais que regulam o número, tamanho e distribuição dos núcleos de povoamento: grandes, médias, pequenas cidades, e ainda minúsculos núcleos semi-rurais, todos são considerados como localidades centrais" (CORRÊA, 1989, p.21).

A centralidade de um núcleo é medida pelo seu grau de importância com base em suas funções centrais: maior número delas, maior a sua região de influência, maior a população externa atendida pela localidade central, maior a sua centralidade. Ou seja, a oferta de bens e serviços está relacionada ao tamanho do núcleo e de sua área de influência. Nesta dinâmica ocorre a hierarquização entre os centros; esta hierarquia é estabelecida da seguinte maneira: metrópole regional, capital regional, centro sub-regional, centro de zona e centro local.

Se por um lado o centro local oferece bens e serviços de uso básico e frequente, por outro, a metrópole regional oferece uma vasta quantidade de bens e serviços que é consumida pela população em razão do seu nível de renda e padrão cultural. Em outras palavras, pelo fato de a metrópole ofertar tanto os bens e serviços frequentes como os menos frequentes, a influência exercida por ela na rede urbana ocupa uma ampla região, atingindo também áreas de influência dos demais centros da rede. Desta forma, a centralidade de um núcleo está fortemente relacionada ao seu grau de importância, que é formulado a partir das suas funções, o que leva a afirmar que quanto maior for o número de funções, maior será a sua área de influência e número de pessoas atendidas (CORRÊA 1989).

Com base nos conceitos de Christaller, percebe-se que os bens e serviços que são consumidos com frequência diária ou semanal demandam reduzido alcance espacial mínimo, pois um pequeno número de pessoas que residam nas proximidades da localidade central justificaria a oferta de bens e serviços desta espécie. Da mesma forma ocorre com o alcance espacial máximo, que também se torna reduzido em consequência dos custos com transporte, "[...] que tornam-se elevados face aos custos dos bens e serviços, que são relativamente baixos" (CORRÊA, 1989, p.22).

A teoria das Localidades Centrais explicita ainda que podem ocorrer variações nos arranjos da rede urbana, referentes às formas como foram estruturados, podendo ser estabelecida a partir do princípio do mercado, onde para um centro de nível hierárquico superior existam três de nível inferior, ou seja, para cada capital regional devem existir três centros locais. Já o princípio do transporte, pressupõe a organização dos principais centros urbanos e das principais vias de circulação. Estas vias se tornam preferenciais para a localização dos centros, fato que resulta no aumento do número dos mesmos. E no princípio administrativo, o número dos centros se amplia e não ocorre superposição de áreas de influência, como nos dois casos anteriores.

Para Corrêa (1982) é necessário considerar que a distribuição, enquanto etapa fundamental entre produção e consumo sob o capitalismo, exerce papel crucial na sociedade e no espaço. Fundamentada na divisão social e territorial do trabalho, a distribuição tem nas cidades os locais preferenciais para sua efetivação, articulada as melhores condições para tal, produzindo uma diferenciação hierárquica entre os centros como significado da própria acumulação capitalista.

0 autor aponta que se deve considerar que a rede de localidades centrais aparece também como uma estrutura territorial, através da qual o processo de reprodução das classes sociais se verifica. Desta forma, a inserção de uma área em determinada divisão territorial do trabalho tem repercussão no arranjo estrutural e espacial da rede de localidades centrais, podendo promover expansão da circulação de mercadorias de acordo com a densidade demográfica, nível de renda, distribuição da mesma, padrões culturais, entre outros.

Nesta perspectiva, cabe apontar que entendemos rede urbana enquanto "[...] um conjunto de centros funcionalmente articulados [...]" (CORRÊA, 1989, p.8), onde é por meio "[...] das numerosas cristalizações materiais diferenciadas do processo de distribuição varejista e de serviços, que se realiza em um amplo território sob o domínio do capitalismo a articulação entre produção propriamente dita e o consumo final [...]" (CORRÊA, 1989, p.20), ou seja, a rede urbana seria a concretização do mercado de distribuição no sistema capitalista.

Geografia Ensino \& Pesquisa, v. 17, n.1 p. 15-26, jan./abr. 2013

Conte. C. H.

ISSN 2236-4994 17 
Deve-se compreender paralelamente que a gênese e a dinâmica de uma rede urbana fazem parte do processo histórico, conferindo a esta uma natureza social, tornando-a uma dimensão socioespacial da sociedade, refletindo e condicionando a sociedade que a engendrou (FRESCA, 2004). Por isso, a rede urbana é "[...] um produto social, historicamente contextualizado, cujo papel crucial é 0 de, através de interações sociais espacializadas, articular toda a sociedade numa dada porção do espaço, garantindo a sua existência e reprodução (CORRÊA, 1997, p.93).

Considerando a rede urbana como uma dimensão socioespacial da sociedade ou como uma estrutura territorial, os processos de criação, apropriação e circulação do capital excedente, ao ocorrer internamente ou externamente a rede, estão em constantes modificações. Isto se dá pelo fato de estarem também relacionados à divisão territorial do trabalho, que por sua vez também sofre mudanças com o passar do tempo.

Esta constatação está vinculada ao entendimento da rede urbana enquanto reflexo e condição para a divisão territorial do trabalho. A rede urbana é considerada como reflexo da divisão territorial do trabalho na medida em que a lógica capitalista diferencia os centros urbanos ou quando os agentes sociais, na intenção de reduzir custos e maximizar lucros, criam vantagens locacionais diferenciadas, processo este que resulta em distintos arranjos espaciais (CORRÊA, 1989).

Na medida em que se valorizam determinadas localidades, outras são desconsideradas naquele momento por não apresentarem elementos necessários para a produção capitalista. Este processo resulta na diferenciação entre as cidades de uma rede urbana, e Fresca $(2004$, p.14) salienta que:

\footnotetext{
A lógica capitalista de acumulação acaba por suscitar, por exemplo, valorização de certas localizações em detrimento de outras, gerando o aumento da importância de algumas cidades. Assim surgem determinadas hierarquias urbanas e certas especializações funcionais. Outras cidades tiveram menor valorização na ótica do capital por não atenderem os requisitos básicos para a produção e reprodução do capital naquele momento, e ainda novos modos de circulação são suscitados e instalados, atingindo, diferenciadamente ou não, os centros de uma rede.
}

A rede urbana torna-se uma condição a partir do momento em que os processos de produção, distribuição, circulação e consumo são realizados e/ou articulados entre as cidades de uma rede. A articulação entre estas cidades se dá na mesma proporção em que evoluem os sistemas de transportes, comunicação e informação interna e externa, permitindo em uma intensidade cada vez maior, a movimentação de pessoas, bens e serviços, capital, idéias, ordens, dentre outros.

Como consequência das necessidades relacionadas à produção, circulação e consumo no âmbito do capitalismo - decisão, produção, concentração, beneficiamento, armazenamento, venda no varejo, consumo final e, ainda, tendo em vista o alcance espacial máximo e mínimo dos consumidores e empresas no amplo território "[...] torna-se necessária a existência de vários pontos interferindo no processo de circulação. Estes pontos são os centros urbanos" (CORRÊA 2006, p. 29).

Souza (2008), aponta que a articulação existente entre as cidades depende da oferta e demanda de bens e serviços que existe entre as mesmas. Muitas cidades, mesmo próximas, não se articulam tão fortemente quanto com cidades maiores e nas quais exista a oferta de bens e serviços mais complexos. Os meios de comunicação, transporte, os fluxos de informação, bens e pessoas, permitem que estas articulações aconteçam. Um exemplo muito frequente de articulação é a busca por tratamentos médicos mais complexos, que torna necessário o deslocamento de pessoas em direção a cidades maiores e geralmente, mais distantes.

Geografia Ensino \& Pesquisa, v. 17, n.1 p. 15-26, jan./abr. 2013

Serviços Educacionais: ferramenta para compreensão do papel de Foz do Iguaçu/ PR na rede urbana
O Instituto Brasileiro de Geografia e Estatística (IBGE), apoiado na teoria das Localidades Centrais e em avanços teóricos, elaborou importantes estudos sobre redes urbanas. 0 primeiro trabalho foi a Divisão do Brasil em Regiões Funcionais Urbanas, elaborado em 1966 (IBGE, 1972); o segundo, as Regiões de Influência das Cidades, elaborado em 1976 (IBGE, 1987); o terceiro em 1993 (IBGE, 2000) e o quarto em 2007 (IBGE, 2008).

A última destas pesquisas (IBGE, 2008) considerou a introdução de novas tecnologias e as consequentes alterações nas redes técnicas, não necessariamente acarretando modificações no 
território. Nesta perspectiva, a organização em várias formas de redes, tendo as cidades como nós, foi ampliada, possibilitando a difusão das funções e das atividades urbanas para diversos núcleos da rede urbana. Para isto, foi utilizada uma gama de variáveis (ausentes nos estudos anteriores), com o intuito de identificar os centros de gestão do território.

Estas variáveis podem ser entendidas por informações de subordinação administrativa no setor público federal, localização das sedes e filiais de empresas, oferta de equipamentos e serviços capazes de dotar uma cidade de centralidade - informações de ligações aéreas, de deslocamentos para internações hospitalares, das áreas de cobertura das emissoras de televisão, da oferta de ensino superior, da diversidade de atividades comerciais e de serviços, da oferta de serviços bancários e da presença de domínio de internet (IBGE, 2008).

Apoiados nestas variáveis foram estabelecidos os fluxos materiais e imateriais, identificando os centros de gestão e a definição das regiões de influência dos centros com base na rede de interações que conectam as cidades (IBGE, 2000). Para tanto, outra hierarquia dos centros foi empregada, desta vez mais complexa, com numerosas subdivisões. Neste sentido, as metrópoles foram subdivididas em grande metrópole nacional, metrópole nacional e metrópole; as capitais regionais em capitais regionais $A, B$ e $C$; os centros sub-regionais foram divididos em $A$ e $B$; os centros de zona em A e B, e os centros locais, abrangendo um total de 4.479 cidades.

Segundo o IBGE (2008), Foz do Iguaçu é considerada um centro sub-regional e sua rede urbana conta com seis cidades: Santa Terezinha de Itaipu, São Miguel do Iguaçu, Medianeira, Serranópolis do Iguaçu, Missal e Itaipulândia, como pode-se observar no mapa 1.

\section{Mapa 1 - Rede urbana de Foz do Iguaçu: 2007}

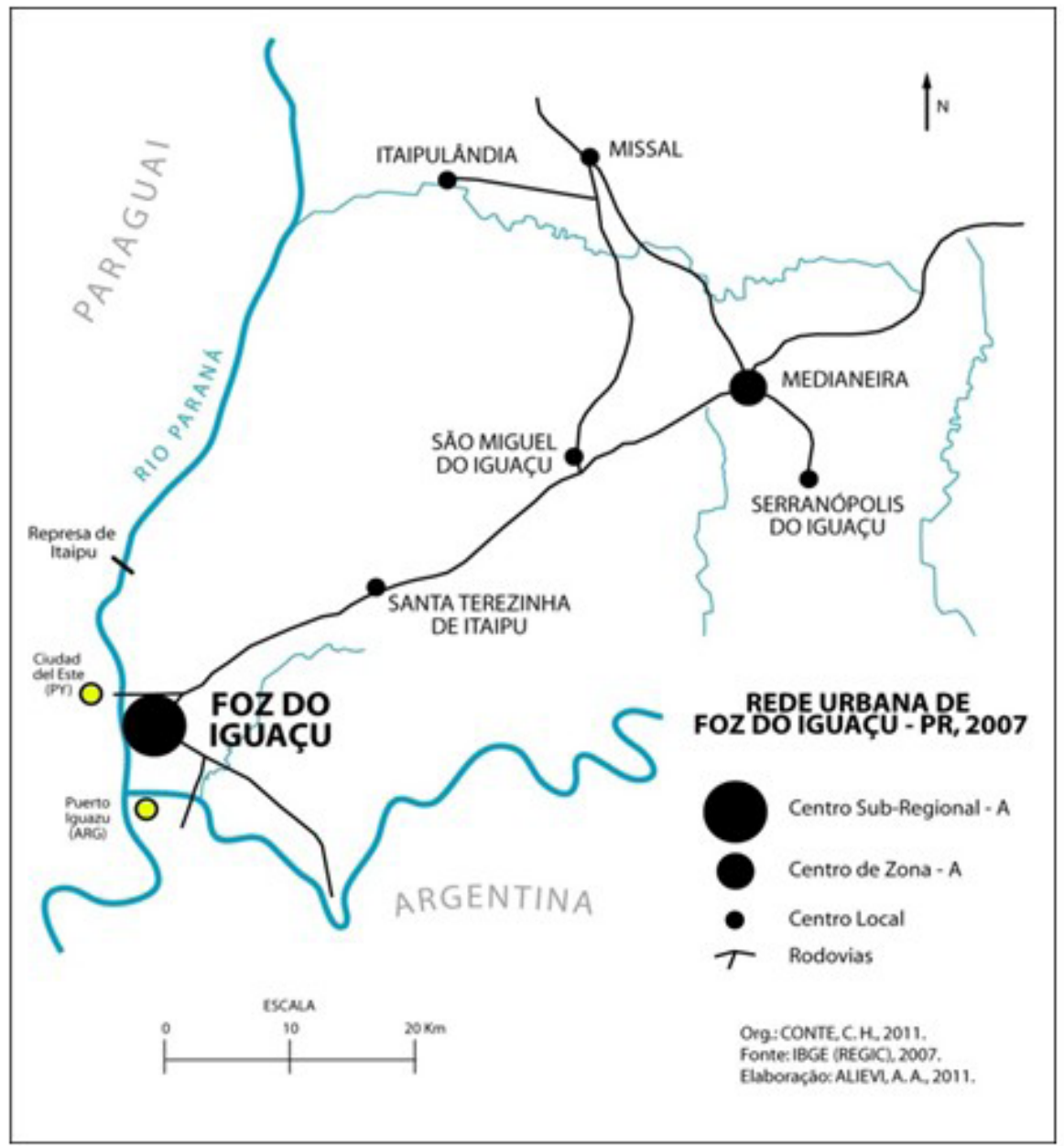

Geografia Ensino \& Pesquisa, v. 17, n.1 p. 15-26, jan./abr. 2013 
Com base na discussão teórica e nos apontamentos acerca da rede urbana regional de Foz do Iguaçu, a próxima parte aborda os serviços de educação existentes em Foz do Iguaçu e a sua importância enquanto elemento para compreensão desta rede de cidades.

\section{Serviço Educacional em Foz do Iguaçu}

A diversificação e a expansão dos serviços ligados ao ensino e à educação em Foz do Iguaçu seguem uma tendência mais ampla, a qual agregou desenvolvimento e crescimento econômico com instrução formal, mas não necessariamente com mudança social (BESSA, 2005). Ocorreu grande crescimento das instituições de ensino, desde a educação infantil até o ensino superior, incluindo os cursos de pós-graduação, de formação profissional de nível técnico e profissionalizante, de acordo com a tabela 1.

Tabela 1 - Número de estabelecimentos, matrículas e docentes em Foz do Iguaçu: 2009. Fonte: IBGE.Cidades@ 2009.

\begin{tabular}{c|c|c|c} 
Nível Escolar & Escolas & Matriculas & Docentes \\
\hline Ensino pré-escolar & 58 & 4.536 & 225 \\
\hline Escola pública municipal & 31 & 2.977 & 135 \\
\hline Escola privada & 02 & 1.559 & 90 \\
\hline Ensino fundamental & 104 & 46.438 & 1.757 \\
\hline Escola pública estadual & 27 & 19.487 & 802 \\
\hline Escola pública municipal & 52 & 20.914 & 549 \\
\hline Escola privada & 25 & 6.037 & 406 \\
\hline Ensino médio & 41 & 12.429 & 824 \\
\hline Escola pública estadual & 27 & 10.516 & 632 \\
\hline Escola privada & 14 & 1.913 & 192
\end{tabular}

1 Criado em 2003 pela Itaipu Binacional, o PTI se consolida como um polo científico e tecnológico no Brasil e no Paraguai. Neste ambiente, o PTI reúne ações voltadas às áreas de Educação, Ciência \& Tecnologia e Empreendedorismo.

Geografia Ensino \& Pesquisa, v. 17, n.1 p. 15-26, jan./abr. 2013

Serviços Educacionais: ferramenta para compreensão do papel de Foz do Iguaçu/ PR na rede urbana

20 ISSN 2236-4994

A tabela 1 apresenta dados referentes ao número de escolas, matrículas e docentes nos níveis pré-escola, fundamental e médio no ano de 2009 , verifica-se que do total de escolas, a maioria (80\%) são públicas - os dados evidenciam nestes níveis escolares forte presença do ensino público. Neste sentido, é importante mencionar a presença do Núcleo Regional de Educação, que abrange os municípios de Foz do Iguaçu, Santa Terezinha de Itaipu, São Miguel do Iguaçu, Itaipulândia, Missal, Ramilândia, Medianeira e Serranópolis do Iguaçu. A presença de alunos de outras cidades da rede regional é mínima, e quando ocorre a presença de alunos provenientes da Argentina e principalmente do Paraguai, se dá em escolas privadas, já que a rede municipal e estadual tem exigências em relação ao local de residência para a utilização do serviço de educação básica da cidade.

Não existe estatística referente ao número de crianças e adolescentes com origem do Paraguai e Argentina que utilizam as escolas de Foz do Iguaçu, mas verifica-se empiricamente que na maior parte são filhos de descendentes de árabes e chineses, os quais residem em Ciudad Del Este e encaminham seus filhos para as escolas privadas da cidade por meio de ônibus e vans particulares.

Relação importante entre cidades da rede urbana e o serviço educacional, encontra-se alicerçada principalmente no ensino superior. Nas últimas décadas foram criadas várias instituições deste segmento, acompanhando, em parte, um processo ocorrido em todo o território nacional, principalmente nas maiores cidades brasileiras. Foz do Iguaçu conta atualmente com oito instituições, das quais cinco são privadas e três públicas.

Dentre as instituições públicas, de acordo com o quadro 1, a cidade abriga o campus da Universidade Estadual do Oeste do Paraná - UNIOESTE, com treze cursos de graduação, um de pós-graduação stricto-sensu e cinco lato-sensu. Entre os cursos de graduação, quatro deles estão ligados às áreas de Engenharia e Ciências Exatas e estão instalados no Parque Tecnológico de Itaipu - PTI'. 
A cidade conta também com a Universidade Aberta do Brasil - UAB, que em parceria com universidades federais do Paraná, de Santa Catarina, de Santa Maria e a Universidade Tecnológica Federal do Paraná, disponibilizam cinco cursos de graduação. A sede da Universidade Aberta do Brasil localiza-se no Parque Tecnológico de Itaipu. Além dos cursos de graduação, a instituição oferece seis cursos de especialização lato-sensu, e prevê a abertura de outros quatro cursos de graduação para o ano de 2012.

A instituição de ensino superior mais recente é a Universidade Federal da Integração Latino-Americana - UNILA, provisoriamente instalada no Parque Tecnológico de Itaipu, cujas atividades tiveram início no segundo semestre de 2009, com a implantação do Instituto de Estudos Avançado. A UNILA foi instituída pela Universidade Federal do Paraná, visando formar pesquisadores e profissionais que pensem a América Latina de forma integrada. Para tanto, as vagas são ocupadas por estudantes brasileiros e dos demais países da América Latina (com um projeto político e acadêmico bilíngue - português/espanhol), com cursos nas áreas de Ciências, Engenharias, Humanidades, Letras, Artes, Ciências Sociais e Aplicadas. A instituição prevê atender dez mil alunos em sua capacidade máxima.

Quadro 1 - Cursos ofertados nas instituições de ensino superior público de Foz do Iguaçu: 2010.

\begin{tabular}{|c|c|c|c|}
\hline Instituição & Área do conhecimento & Cursos & Total \\
\hline \multirow{3}{*}{$\begin{array}{l}\text { Universidade Esta- } \\
\text { dual do Oeste do } \\
\text { Paraná }\end{array}$} & Ciências Sociais Aplicadas & $\begin{array}{l}\text { Administração, Ciências Contábeis, Direito, Hotelaria e } \\
\text { Turismo }\end{array}$ & 05 \\
\hline & Educação e Letras & $\begin{array}{l}\text { Enfermagem, Letras - Português/Espanhol, Letras - } \\
\text { Português/Inglês e Pedagogia }\end{array}$ & 04 \\
\hline & Engenharia e Ciências Exatas & $\begin{array}{l}\text { Ciências da Computação, Engenharia Elétrica, Enge- } \\
\text { nharia Mecânica e Matemática }\end{array}$ & 04 \\
\hline \multirow{4}{*}{$\begin{array}{l}\text { Universidade } \mathrm{Fe}- \\
\text { deral da Integração } \\
\text { Latino Americana }\end{array}$} & Ciências Exatas Aplicadas & Ciências Econômicas & 01 \\
\hline & Ciências Biológicas & Ciências Biológicas & 01 \\
\hline & Ciências Humanas & $\begin{array}{l}\text { Ciência Política e Sociologia e Relações Internacionais } \\
\text { e Integração }\end{array}$ & 02 \\
\hline & Engenharias & $\begin{array}{l}\text { Engenharia Civil de infraestrutura e Engenharia de } \\
\text { Energias Renováveis }\end{array}$ & 02 \\
\hline \multirow{3}{*}{$\begin{array}{l}\text { Universidade Aber- } \\
\text { ta do Brasil }\end{array}$} & Ciências Sociais Aplicadas & Administração Pública, Tecnólogo em Gestão Pública & 02 \\
\hline & Ciências Humanas & Sociologia & 01 \\
\hline & Educação e Letras & Letras - Português/Espanhol e Educação Especial & 02 \\
\hline \multicolumn{3}{|l|}{ Total } & 24 \\
\hline
\end{tabular}

Fonte: UNIOESTE, UNILA e UAB, 2010.

O crescimento das instituições de ensino superior foi mais significativo em relação as privadas, como se pode notar no Quadro 2. Entretanto, esse crescimento se deu a partir dos anos 2000, com a criação da União Dinâmica de Faculdades Cataratas em 2000, da Faculdade União das Américas em 2001, e da Faculdade Anglo-Americano em 2003. As outras duas instituições são o Centro de Ensino Superior de Foz do Iguaçu e Faculdades Unificadas de Foz do Iguaçu, criadas em 1993. Juntas, as instituições privadas ofertam um total de 77 cursos de graduação em distintas áreas do conhecimento, além de uma vasta lista de pós-graduação em nível lato-sensu. 
Quadro 2 - Cursos ofertados nas instituições de ensino superior privado em Foz do Iguaçu: 2010.

\begin{tabular}{|c|c|c|c|}
\hline Instituição & Área do conhecimento & Cursos & Total \\
\hline \multirow[t]{3}{*}{$\begin{array}{l}\text { Faculdades Anglo } \\
\text { Americano }\end{array}$} & Ciências Exatas Aplicadas & $\begin{array}{l}\text { Administração, Ciência da Computação, Comércio Exterior, } \\
\text { Gestão Ambiental, Marketing e Relações Internacionais }\end{array}$ & 06 \\
\hline & $\begin{array}{l}\text { Ciências Biológicas e da } \\
\text { Saúde }\end{array}$ & $\begin{array}{l}\text { Ciências Biológicas, Farmácia, Fisioterapia Psicologia e } \\
\text { Educação Física }\end{array}$ & 06 \\
\hline & Ciências Humanas & Pedagogia & 01 \\
\hline \multirow{4}{*}{$\begin{array}{l}\text { Centro de Ensino } \\
\text { Superior de Foz } \\
\text { do lguaçu }\end{array}$} & Ciências Exatas Aplicadas & $\begin{array}{l}\text { Administração, Ciências Contábeis, Ciência da Computa- } \\
\text { ção, Ciências Econômicas, Tecnologia em Processamento } \\
\text { de Dados }\end{array}$ & 05 \\
\hline & $\begin{array}{l}\text { Ciências Biológicas e de } \\
\text { Saúde }\end{array}$ & Enfermagem, Farmácia, Fisioterapia, Educação Física & 04 \\
\hline & Ciências Humanas & Comunicação Social, Direito, Psicologia e Turismo & 04 \\
\hline & Graduação tecnológica & $\begin{array}{l}\text { Comunicação e Ilustração Digital, Comunicação Empre- } \\
\text { sarial, Comunicação para Web, Gerenciamento de Redes } \\
\text { de Computadores, Gestão Comércio Exterior, Gestão Em- } \\
\text { preendedora, Gestão de Empreendimentos Esportivos, } \\
\text { Gestão Eventos, Gestão Hospitalar, Gestão de Marketing, } \\
\text { Gestão de Recursos Humanos, Gestão de Sistemas de In- } \\
\text { formação, Gestão de Turismo Receptivo, Multimídia, Pro- } \\
\text { dução Gráfica Digital e Redes de Computadores } \\
\end{array}$ & 16 \\
\hline \multirow{4}{*}{$\begin{array}{l}\text { União Dinâmica } \\
\text { de Faculdades } \\
\text { Cataratas }\end{array}$} & Ciências Exatas Aplicadas & $\begin{array}{l}\text { Administração, Administração Pública, Ciências Contábeis, } \\
\text { Engenharia Ambiental, Engenharia Civil, Gestão de Negó- } \\
\text { cios, Sistema de Informações }\end{array}$ & 07 \\
\hline & $\begin{array}{l}\text { Ciências biológicas e de } \\
\text { Saúde }\end{array}$ & Agronomia, Enfermagem & 02 \\
\hline & Ciências Humanas & $\begin{array}{l}\text { Arquitetura e Urbanismo, Design de Moda, Direito, Jorna- } \\
\text { lismo, Publicidade e Propaganda, Relações Públicas eT- } \\
\text { turismo }\end{array}$ & 07 \\
\hline & Educação e Letras & Letras e Pedagogia & 02 \\
\hline \multirow{3}{*}{$\begin{array}{l}\text { Faculdade União } \\
\text { das Américas }\end{array}$} & Ciências Exatas Aplicadas & Administração, Engenharia Ambiental, & 04 \\
\hline & $\begin{array}{l}\text { Ciências biológicas e da } \\
\text { Saúde }\end{array}$ & $\begin{array}{l}\text { Biomedicina, Ciências Biológicas, Enfermagem, Farmácia, } \\
\text { Fisioterapia, Nutrição. }\end{array}$ & 12 \\
\hline & Ciências Humanas & $\begin{array}{l}\text { História, Psicologia, Secretariado Executivo Trilingue, Ser- } \\
\text { viço Social e Pedagogia }\end{array}$ & 07 \\
\hline \multirow{2}{*}{$\begin{array}{l}\text { Faculdades Unifi- } \\
\text { cadas de Foz do } \\
\text { lguaçu }\end{array}$} & Ciências Exatas Aplicadas & Administração & 01 \\
\hline & Ciências Humanas & Direito e Hotelaria & 02 \\
\hline \multicolumn{3}{|l|}{ Total } & 77 \\
\hline
\end{tabular}

Fonte: Faculdades Anglo-Americano, Cesufoz, UDC, Unifoz, 2010.

Destaque também para a implantação do Parque Tecnológico de Itaipu, que agrega em seu espaço laboratórios de última geração, plataforma de ensino à distância e diversos outros projetos educacionais. O PTI apoia a criação e a consolidação de empresas inovadoras através do programa $\mathrm{PTI}$ - Empreendedorismo, por meio da Fábrica de Empreendimento, da Incubadora Empresarial e do Condomínio Empresarial, oferecendo suporte operacional e gerencial para as empresas, assim como a interação com o meio empresarial, científico e de financiamento, colaborando com a inserção e consolidação destas empresas.

Além das faculdades e universidades presentes em Foz do Iguaçu, ocorre a expansão de p. $15-26$, jan./abr. 2013

Serviços Educacionais: ferramenta para compreensão do papel de Foz do Iguaçu/ PR na rede urbana pus do Instituto Federal do Paraná - IFPR, oferecendo dois cursos e com previsão de abertura de novos. A cidade conta ainda com outras nove instituições de cursos profissionalizantes.

O ensino superior, ao contrário do ensino fundamental e médio, não é utilizado apenas pela população iguaçuense, conforme mostra a tabela 1. Dos 11.121 alunos matriculados nas oito insti- 
tuições consultadas, 8.927 são estudantes de Foz do Iguaçu, 1.803 compõem o grupo de estudantes que se deslocam de cidades localizadas no Oeste paranaense, 91 são provenientes de Ciudad Del Este e Puerto Iguazu e os outros 300 são originários de outras localidades.

Observa-se novamente a pouca participação de paraguaios e argentinos, já que somam apenas 91 estudantes. Estes se reúnem no projeto educacional UNILA, ou seja, antes de 2009 a representatividade de estudantes dos países fronteiriços em Foz do Iguaçu era praticamente inexistente. Parte desta situação pode ser explicada pela existência de instituições de ensino público nestes países.

Tabela 2 - Número de alunos e origem nas IES de Foz do Iguaçu: 2010

\begin{tabular}{l|l|l|l|l|l} 
Instituição & Total & $\begin{array}{l}\text { Foz do } \\
\text { Iguaçu }\end{array}$ & $\begin{array}{l}\text { Região } \\
\text { Oeste/ } \\
\text { PR }\end{array}$ & $\begin{array}{l}\text { Puerto Iguazu/ } \\
\text { AR e Ciudad del } \\
\text { Este/PY }\end{array}$ & $\begin{array}{l}\text { Outras lo- } \\
\text { calidades }\end{array}$ \\
\hline $\begin{array}{l}\text { Universidade Estadual do Oeste do } \\
\text { Paraná }\end{array}$ & 1.455 & 982 & 295 & 1 & 177 \\
\hline $\begin{array}{l}\text { Universidade Federal de Integração } \\
\text { latino Americana }\end{array}$ & 205 & 57 & - & 90 & 58 \\
\hline Universidade Aberta do Brasil & 850 & 602 & 210 & - & 38 \\
\hline Anglo Americano & 1.234 & 884 & 350 & - & - \\
\hline $\begin{array}{l}\text { Centro de Ensino Superior de Foz } \\
\text { do Iguaçu }\end{array}$ & 1.215 & 966 & 249 & - & - \\
\hline $\begin{array}{l}\text { União Dinâmica de Faculdades Ca- } \\
\text { taratas }\end{array}$ & 3.500 & 3.083 & 398 & - & 19 \\
\hline Faculdade União das Américas & 2229 & 1963 & 258 & - & 8 \\
\hline $\begin{array}{l}\text { Faculdades Unificadas de Foz do } \\
\text { lguaçu }\end{array}$ & 433 & 390 & 43 & - & - \\
\hline TOTAL & 11.121 & 8.927 & 1.803 & 91 & 300
\end{tabular}

Fonte: UniOeste, Unila, UAB, Faculdades Anglo-Americano, Cesufoz, UDC, Uniamérica, Unifoz, 2010.

Das 17 cidades do Oeste paranaense que utilizam o ensino superior existente em Foz do Iguaçu, 12 pertencem a rede urbana regional estabelecida pelo IBGE em 1993. Não foi possível estabelecer a origem e o número de estudantes de cada cidade, pois algumas instituições apresentaram apenas o número total de alunos e as cidades de origem.

No Oeste paranaense existem outros dois polos educacionais, Cascavel e Toledo, cabendo mencionar que as áreas de conhecimento e os cursos distinguem-se uns dos outros, permitindo desta forma um intenso intercâmbio entre os estudantes destas cidades. Em relação às cidades mais próximas de Foz do Iguaçu, verifica-se que em Santa Terezinha de Itaipu não existe nenhuma instituição de ensino superior, São Miguel do Iguaçu conta com uma e Medianeira possui duas. Outras cidades, como Itaipulândia, Missal, Ramilândia, Céu Azul, Matelândia e Serranópolis do Iguaçu não possuem instituições de ensino superior.

O transporte destes alunos é feito em grande parte através da contratação de empresas privadas de transporte. No período noturno é comum encontrar esses ônibus nas principais vias de acesso às faculdades e universidades. Geralmente cada ônibus sai de uma única cidade e distribui os alunos nas respectivas instituições, concentrando-se no final deste processo em frente à Unioeste, considerada como a universidade mais distante dentro da malha urbana de Foz do Iguaçu.

\section{Considerações Finais}

No decorrer da pesquisa verificamos que a rede urbana regional de Foz do Iguaçu é uma rede com poucos núcleos urbanos, apresentando uma distância relativamente elevada entre os mesmos, se comparado a outras redes regionais do Paraná. Isso está relacionado com o processo de ocupação, visto que até a década de 1940 poucos foram os núcleos criados. Após 1940, os

Geografia Ensino \& Pesquisa, v. 17, n.1 p. 15-26, jan./abr. 2013

Conte. C. H.

ISSN 2236-4994 
processos de ocupação das terras foram pautados em loteamentos rurais - com predomínio de pequenos estabelecimentos -, e urbanos, mas como já havia melhor infraestrutura de transporte sendo estabelecida, criaram-se menos núcleos urbanos e a distância entre eles foi maior.

De acordo com o IBGE (2008), Foz do Iguaçu foi considerada como um centro sub-regional, com relações econômicas e sociais relativamente restritas com as demais cidades. Foz do Iguaçu perdeu seis cidades em sua rede urbana em relação à pesquisa de 1993: Matelândia, Ramilândia, Céu Azul, Vera Cruz do Oeste, Diamante do Oeste, Santa Helena e São José das Palmeiras; visto que estas cidades passaram a compor a rede urbana regional de Cascavel.

Contudo, os serviços educacionais existentes em Foz do Iguaçu tornam a rede urbana bastante dinâmica, já que além de atender as cidades que compõe sua rede regional de cidades, expande sua atuação para outras redes regionais paranaenses, bem como de outros estados e países.

Esta expansão do ensino superior em Foz do Iguaçu denota a perspectiva de torná-la importante polo de ensino superior no Oeste do Paraná. A cidade vem consolidando-se como centro de ensino superior, com área de atuação relativamente expressiva. A implantação de novas instalações universitárias tem ocorrido ao longo do eixo das principais vias de acesso às universidades e faculdades, com destaque para a Avenida Tancredo Neves, onde o mercado imobiliário dinamiza-se com a construção de condomínios horizontais de moradias para diferentes classes sociais. A chegada de novos alunos e professores vindos de diferentes partes do Brasil e da América Latina tem aquecido a economia.

Referências

BESSA, K. C. Reestruturação da rede urbana brasileira e cidades médias: o exemplo de Uberlândia (MG). Caminhos da Geografia. Uberlândia, v. 24, n.16, out. 2005.

CORRÊA, R. L. A rede urbana. São Paulo: Ática, 1989.

R. L. Repensando a teoria das localidades centrais. In: SANTOS, M (Org.). Novos Rumos da Geografia Brasileira. São Paulo: Hucitec, 1982.

R. L. Trajetórias geográficas. Rio de Janeiro: Bertrand Brasil, 1997.

R. L. Estudos sobre a rede urbana. Rio de Janeiro: Bertrand Brasil, 2006.

FRESCA, T. M. A rede urbana do norte do Paraná. Londrina: Eduel, 2004.

IBGE. Cidades@. Disponível em: < http://www.ibge.gov.br/cidadesat/topwindow.htm?1>. Acesso em: 11 agosto 2011.

IBGE. Regiões de Influência das Cidades. 1993. Rio de janeiro, 2000.

Regiões de Influência das Cidades ,2007. Rio de Janeiro, 2008.

IPARDES. Os Vários Paranás - oeste paranaense: $03^{\circ}$ espaço relevante. Curitiba, 2008. PREFEITURA MUNICIPAL DE FOZ DO IGUAÇU. Anuário Estatístico 2007. Foz do Iguaçu, 2008.

Geografia Ensino \& Pesquisa, v. 17, n.1 p. 15-26, jan./abr. 2013
SOUZA, M. L. de. ABC do Desenvolvimento Urbano. $4^{\text {a }}$ Ed. Rio de Janeiro: Bertrand Brasil, 2008.
Serviços Educacionais: ferramenta para compreensão do papel de Foz do Iguaçu/ PR na rede urbana 


\section{Correspondência:}

Cláudia Heloiza Conte- Rua Salto União, 163, Jardim Cataratas, Foz do Iguaçu-PR

E-mail: claudiaheloiza@yahoo.com.br

Recebido em 19 de abril de 2012.

Revisado pelo autor em 08 de outubro de 2012.

Aceito para publicação em 09 de outubro de 2012. 